\title{
Пространственно-авторегрессионный анализ склонности к легочным заболеваниям у жителей Российской Федерации
}

\author{
Артур Нагапетян*, Максим Попов, Анастасия Петрухина \\ Дальневосточный федеральный университет, Владивосток, Россия
}

\author{
Информация о статье \\ Поступила в редакиию: \\ 15.02 .2021 \\ Принята \\ $\kappa$ опубликованию: \\ 26.02.2021
}

УДК 330.43

JEL I15

\begin{abstract}
Аннотация
Основная задача исследования заключается в том, чтобы выяснить, повысится ли склонность к заболеваниям органов дыхания у населения в рассматриваемом регионе при прочих равных условиях, если вырастут соответствующие показатели в соседних регионах. С одной стороны, если окружаюшүие являются носителями лёгочных заболеваний, то заболеем и мы. С другой стороны, если в соседних регионах высокие показатели лёгочной заболеваемости населения, то люди, проживающие в исследуемом нами регионе, будут уже адаптированы $\kappa$ подобного рода заболеваниям, ведь они сталкивались с ними ранее, и у них выработался иммунитет к болезням данного типа. Для исследования были выделены различные сочиально-экономические факторы, полученные из статей отечественных и зарубежных ученых, с помощью эконометрических методов пространственно-регрессионного анализа отобраны переменные, влияющие на показатель склонности к заболеваемости. Выводы работы основываются на построенных моделях и подтверждают результаты исследований на зарубежных выборках, демонстрирующих влияние уровня выбросов загрязняющих веществ на склонность к заболеваниям органов дыхания местного населения.
\end{abstract}

\section{Spatial Autoregressive Analysis of the Tendency to Respiratory Diseases}

Artur Nagapetyan, Maksim Popov, Anastasia Petrukhina

\section{Keywords:}

diseases, respiratory organs, socio-economic factors, air pollution, spatial analysis of morbidity, mortality, lung cancer, asthma, tuberculosis, income

\begin{abstract}
Research problem: will the propensity to respiratory diseases increase in the region under consideration, all other things being equal, if the corresponding indicators increase in neighboring regions? On the one hand, if people around us are carriers of lung diseases, then we will also get sick. On the other hand, if the neighboring regions have high rates of lung disease, then the people living in the region we study will already be adapted to this type of disease, because they have encountered them before and may develop immunity to this type of disease. Also, the influence of factors characterizing the level of socio-economic development of regions on the indicator, such as real income per capita, age dependency ratio, the number of doctors, the tendency to diseases of the blood, the level of development of
\end{abstract}

* Автор для связи: nagapetyan_ar@dvfu.ru DOI: https://dx.doi.org/10.24866/2311-2271/2021-1/5-14 
the road network, emissions of pollutants etc. The conclusions of the work confirm the results of research on foreign samples that demonstrate the influence of the level of pollutants emissions on the propensity to respiratory diseases of the local population. Based on the results obtained, it is possible to describe the reasons more reasonably for interregional differentiation of the studied indicator, which may be important when planning roadmaps to counter potential epidemiological risks.

\section{Введение}

В работе исследуются причины возрастания уровня заболеваемости населения раком лёгких, астмой, туберкулёзом, хронической обструктивной болезнью лёгких (далее - ХОБЛ). На рост таких болезней оказывают влияние такие социально-экономические факторы, как высокий уровень урбанизации, вследствие чего возникает загрязнение воздуха в открытом пространстве и в помещении, курение, доход населения, а также социальный статус человека.

Исследовательская проблема: повысится ли склонность к заболеваниям органов дыхания в рассматриваемом нами регионе при прочих равных условиях, если вырастут соответствующие показатели в соседних регионах? С одной стороны, если окружающие являются носителями лёгочных заболеваний, то заболеем и мы, с другой стороны, если в соседних регионах высокие показатели лёгочной заболеваемости населения, то люди, проживающие в исследуемом нами регионе, будут уже адаптированы к подобного рода заболеваниям, ведь они сталкивались с ними ранее, и у них выработался иммунитет к болезням данного типа. Для исследования были выделены различные социально-экономические факторы, полученные из статей отечественных и зарубежных ученых, с помощью эконометрических методов пространственно-регрессионного анализа отобраны переменные, влияющие на показатель склонности к заболеваемости. Основной новизной данного исследования является учет факторов влияния соседей при моделировании легочной заболеваемости в регионах России на основе методов пространственно-авторегрессионного анализа для выявления влияния социально-экономических факторов на легочную заболеваемость.

Целью исследования является разработка теоретических и практических предложений по моделированию уровня заболеваемости органов дыхания с учетом межпространственных взаимосвязей.

\section{Обзор литературы}

Проводится анализ влияния различных социально-экономических факторов на болезни, связанные с органами дыхания. В работе рассмотрены такие факторы, как загрязнение воздуха, влияние этнической принадлежности, дохода населения и общего состояния окружающей среды на распространение респираторных заболеваний, развитие астмы, рака легких и других болезней органов дыхания.

Так, на примере китайской провинции Сюаньвэй со значительной высокой смертностью от рака лёгких в 1970-х гг. было исследовано влияние загрязнения воздуха в помещениях и употребления табака на заболевание раком лёгких [1]. Исследователи оценили взаимосвязь между загрязнением воздуха в помещениях, употреблением табака и риском развития рака легких, чтобы продолжить изучение воздействия этих двух факторов риска, построив безусловную регрессионную логистическую модель. Группа исследователей провела опрос в провинции, обнаружив, что в районах, где потребление дымного угля за 30 лет снизилось, влияние употребления табака на заболеваемость раком легких стало значительно выше.

Еще одним фактором, негативно сказывающимся на здоровье примерно $50 \%$ населения мира, является использование в качестве топлива угля и биомассы. 
Люди нехотя поддаются влиянию вредных веществ, отсюда и возникают такие болезни, как рак легких у женщин, ХОБЛ у мужчин и туберкулез. По оценкам Всемирной организации здравоохранения, более 1,6 млн смертей могут объясняться наличием в помещении дыма от твердого топлива. В работе [2] представлена информация о данных, свидетельствующих о воздействии твердого топлива из биомассы на заболевания органов дыхания. Эту проблему также рассмотрели другие исследователи [3], они провели метаанализ, чтобы установить связь между ХОБЛ и воздействием дыма из биомассы у женщин. Люди, подвергшиеся воздействию биомассы, в 1,38 раз чаще имели диагноз ХОБЛ, чем не подвергшиеся воздействию. В итоге выявлена значительная связь между ХОБЛ и воздействием дыма на биомассу для женщин, живущих как в сельской местности, так и в городах.

Статья [4] посвящена влиянию загрязнения воздуха на лёгочные заболевания, также эта проблема описывается другими исследователями в работах $[5,6]$. Исследования были проведены в городах США и Италии. Было выяснено, что астма, хроническая болезнь легких, рак легких и респираторные инфекции усугубляются из-за воздействия различных загрязнителей воздуха окружающей среды с наибольшим воздействием твердых частиц, озона и оксидов азота. Многие развивающиеся страны получают энергию из природных, недорогих источников для промышленных, коммерческих и бытовых целей, но не располагают достаточными технологиями для смягчения потенциального загрязнения воздуха, возникающего в результате использования этих источников энергии. Данными исследователями также было выяснено, что почти 9 из 10 человек, проживающих в городских районах по всему миру, страдают от загрязнения. Основным источником глобального загрязнения воздуха в домашних хозяйствах является неполное сжигание биотоплива, в результате которого образуются высокие уровни химических компонентов, таких как оксиды серы, оксиды азота, твердые частицы и другие. Влияние загрязнения воздуха на распространение лёгочных заболеваний также подробно описывается в статьях [7-11].

В статье [12] рассматривается влияние быстрой урбанизации во всем мире в связи с более интенсивным потреблением энергии и увеличением выбросов из транспортных и промышленных источников. В городе появление загрязняющих веществ связано с дорожным движением, которое способствует развитию аллергии. В результате эпидемиологических наблюдений исследователи видят возможную связь между хроническим воздействием токсичного воздуха в детском возрасте и уязвимостью к ХОБЛ во взрослом возрасте, и что у детей, подвергшихся более высоким пренатальным уровням загрязнения воздуха, может быть повышенный риск развития респираторных заболеваний.

В [13] исследователи предполагают, что на заболевания органов дыхания могут также влиять этническая принадлежность и социально-экономическое положение семей. Исследования были проведены на основе различных семей из Британии и США, были учтены показатели, например, социально-экономический статус, то есть дохода домохозяйства, профессиональная деятельность, материнский возраст при вступлении в материнство, материнский статус занятости, курение родителей, размер семьи, присутствие в доме пушистых домашних животных и маркер питания (начало грудного вскармливания). Данная статья позволяет предположить, что дети из числа этнических меньшинств, включая такие этнические группы с более низкой распространенностью астмы, как, например, выходцы из Южной Азии, с большей вероятностью будут госпитализированы по причинам, связанным с астмой, чем белые, а высокий уровень госпитализации свидетельствует о различной степени тяжести астмы у белых и южно-азиатских детей или 
о случаях астмы и одышки. Результаты некоторых исследований свидетельствуют о том, что у детей из групп этнических меньшинств наблюдается недостаточная диагностика астмы. В итоге следует отметить, что этнические группы разнообразны как по распространенности астмы и болезней, так и по социальным, экономическим и культурным характеристикам, поэтому необходимо исследовать каждую этническую группу отдельно. Потенциальные объяснения наблюдаемых различий, которые действительны для одной группы, не обязательно выполняются для других групп.

В Латинской Америке астма является одним из весьма распространённых заболеваний. Прежде всего, это связано с социальным неравенством, которое проявляется на данном континенте [14]. Было выяснено, что во всем мире астмой болеют около 300 млн человек, из которых 40 млн находятся в Латинской Америке. Популяционные исследования показали, что неатопическая астма у латиноамериканских детей ассоциировалась с большим воздействием «грязи», плохого питания, ожирения и психосоциальных расстройств. Городская беднота, страдающая самой высокой распространенностью астмы, живет в некачественном и переполненном жилье и в районах, часто имеющих ограниченный или вообще отсутствующий доступ к основным услугам, включая чистую воду, санитарию и медицинские ресурсы. Экологические исследования городов Бразилии или стран Латинской Америки показали, что повышенная распространенность астмы связана с бедностью, неравенством (измеряется индексом Джини) и уровнем смертности от внешних причин (показатель контекстуального стресса). В таких условиях интенсивного воздействия раздражителей окружающей среды, усугубляемых скученностью домашних хозяйств и необходимостью для работающих женщин оставлять своих детей в переполненных детских садах, где передача вирусных инфекций дыхательных путей весьма интенсивная, из-за чего высокая доля младенцев и маленьких детей имеет повторяющиеся хрипы в раннем возрасте и бронхиальную гиперреактивность.

Одной из распространенных болезней является туберкулез. В работе [15] исследуется влияние факторов, характеризующих социально-экономические, демографические и экологические условия проживания населения на заболеваемость туберкулезом органов дыхания в Томской области. Содержание загрязняющих веществ в атмосферном воздухе и концентрация нитратов в питьевой воде являются основными причинами возникновения данной болезни. Авторы проводили анализ заболеваемости туберкулезом по материалам документа под названием «Сведения об инфекционных и паразитарных заболеваниях», в которой отражены все случаи заболеваний с самого первого установленного диагноза на территории, включая лиц без определенного места жительства. В работе выделяются такие показатели, влияющие на появление болезни:

- демографические факторы;

- экономическое состояние территории;

- уровень благоустройства жилищ;

- медико-биологические факторы;

- питание населения;

- уровень техногенной нагрузки;

Авторами было доказано, что уровень заболеваемости туберкулезом в районах Томской области разный, потому что различные социальные, экономические и экологические условия для проживания населения в районах этой области. Исходя из исследований можно сделать вывод, что выявленные показатели могут распространяться и на другие города России, в совокупности влиять на развитие туберкулеза. 
В ходе анализа литературы были выведены основные факторы, которые способствуют появлению и развития болезней органов дыхания. Часто эти болезни становятся хроническими или приводят к смерти, то есть они неизлечимы. Этими факторами являются различные загрязнения воздуха, уровень экономического и социального положения людей в обществе, географическое положение и иногда этническая принадлежность. Однако нельзя применять факторы ко всем странам, так как проявляются они везде по-разному, но негативное влияние оказывают в равной степени.

\section{Данные и модели}

Используя данные Федеральной службы государственной статистики Российской Федерации [16] и учитывая наличие и достоверность необходимых данных с частичным сглаживанием влияния «пропущенных переменных» из-за применения эконометрических методов пространственно-регрессионного анализа, были отобраны некоторые переменные, воздействие которых на показатель склонности к заболеваемости органов дыхания будет исследоваться в работе (табл. 1).

Таблица 1

Факторы, оказывающие влияние на исследуемую переменную

\begin{tabular}{|c|c|c|c|}
\hline № & Обозначение & Фактор & Способ расчета \\
\hline 1 & $\mathrm{x} 1$ & $\begin{array}{l}\text { Склонность к заболеваниям ор- } \\
\text { ганов дыхания }\end{array}$ & $\begin{array}{l}\text { Заболеваемость на } 1000 \text { человек. Бо- } \\
\text { лезни органов дыхания }\end{array}$ \\
\hline 2 & $x 56$ & $\begin{array}{l}\text { Реальные доходы на душу } \\
\text { населения }\end{array}$ & $\begin{array}{l}\text { Номинальные доходы разделены на } \\
\text { стоимость фиксированного набора по- } \\
\text { требительских товаров и услуг }\end{array}$ \\
\hline 3 & $\mathrm{x} 57$ & Уровень образованности & $\begin{array}{l}\text { Оценка доли населения с высшим об- } \\
\text { разованием в регионе }\end{array}$ \\
\hline 4 & $\mathrm{x} 18$ & $\begin{array}{l}\text { Коэффициент } \\
\text { демографической нагрузки }\end{array}$ & $\begin{array}{l}\text { Сколько лиц нетрудоспособных воз- } \\
\text { растов приходится на } 1000 \text { человек } \\
\text { трудоспособного возраста }\end{array}$ \\
\hline 5 & $\mathrm{x} 39$ & $\begin{array}{l}\text { Уровень развития финансовой } \\
\text { инфраструктуры в регионе }\end{array}$ & $\begin{array}{l}\text { Число кредитных организаций и фи- } \\
\text { лиалов в субъекте }\end{array}$ \\
\hline 6 & $\mathrm{x} 41$ & Уровень преступности & $\begin{array}{l}\text { Число зарегистрированных убийств и } \\
\text { покушений на убийство }\end{array}$ \\
\hline 7 & $\mathrm{x} 17$ & Уровень присутствия женщин & На 1000 мужчин приходится женщин \\
\hline 8 & $\mathrm{x} 19$ & Уровень брачности & $\begin{array}{l}\text { Общие коэффициенты брачности на } \\
1000 \text { человек населения }\end{array}$ \\
\hline 9 & $\mathrm{x} 25$ & Уровень безработицы & $\begin{array}{l}\text { По данным выборочных обследований } \\
\text { рабочей силы; в среднем за год }\end{array}$ \\
\hline 10 & $x 53$ & Уровень автомобилизации & $\begin{array}{l}\text { Число собственных легковых автомо- } \\
\text { билей на } 1000 \text { человек населения }\end{array}$ \\
\hline 11 & $\mathrm{x} 55$ & Склонность к кредитованию & $\begin{array}{l}\text { Отношение объема кредитов на од- } \\
\text { ного человека (без учета нетрудоспо- } \\
\text { собных) к величине номинальных до- } \\
\text { ходов на душу населения }\end{array}$ \\
\hline 12 & $\mathrm{x} 5$ & $\begin{array}{l}\text { Уровень обеспеченности } \\
\text { больничными койками }\end{array}$ & $\begin{array}{l}\text { Число больничных коек на } 10000 \text { че- } \\
\text { ловек населения }\end{array}$ \\
\hline 13 & $x 6$ & $\begin{array}{l}\text { Уровень обеспеченности } \\
\text { врачами }\end{array}$ & $\begin{array}{l}\text { Численность населения на одного } \\
\text { врача }\end{array}$ \\
\hline 14 & $\mathrm{x} 8$ & $\begin{array}{l}\text { Склонность к заболеваниям си- } \\
\text { стемы кровообращения }\end{array}$ & $\begin{array}{l}\text { Заболеваемость на } 1000 \text { человек. Бо- } \\
\text { лезни системы кровообращения }\end{array}$ \\
\hline 15 & $\mathrm{x} 9$ & $\begin{array}{l}\text { Склонность к заболеваниям } \\
\text { крови, кроветворных органов и } \\
\text { отдельные нарушения, вовле- } \\
\text { кающие иммунный механизм }\end{array}$ & $\begin{array}{l}\text { Заболеваемость на } 1000 \text { человек. Бо- } \\
\text { лезни крови, кроветворных органов и } \\
\text { отдельные нарушения, вовлекающие } \\
\text { иммунный механизм }\end{array}$ \\
\hline
\end{tabular}




\begin{tabular}{|r|c|l|l|}
\hline $\mathbf{1 6}$ & $\mathrm{x} 52$ & $\begin{array}{l}\text { Уровень развития дорожной } \\
\text { сети }\end{array}$ & $\begin{array}{l}\text { Плотность автомобильных дорог об- } \\
\text { щего пользования с твердым покры- } \\
\text { тием }\end{array}$ \\
\hline $\mathbf{1 7}$ & $\mathrm{x} 66$ & $\begin{array}{l}\text { Уровень выбросов } \\
\text { загрязняющих веществ }\end{array}$ & $\begin{array}{l}\text { Выбросы загрязняющих веществ, от- } \\
\text { ходящих от стационарных источников } \\
\text { на 1 чел. }\end{array}$ \\
\hline $\mathbf{1 8}$ & $\mathrm{x} 28$ & $\begin{array}{l}\text { Уровень производительности } \\
\text { труда }\end{array}$ & Оценка ВРП на одного занятого \\
\hline
\end{tabular}

Источник: составлено авторами

Для оценки вышеприведенных факторов будут использованы модели: линейная регрессионная модель на основе пространственной выборки (Pooled Regression) (1), модели панельных данных с фиксированными (2) и случайными эффектами (3), модели с пространственно-авторегрессионными эффектами $(4,5)$.

$$
\begin{array}{rl}
x 1_{i}=\beta_{0}+\beta_{1} & * x 56_{i}+\beta_{2} * x 57_{i}+\beta_{3} * x 18_{i}+\beta_{4} * x 39_{i}+\beta_{5} * x 41_{i}+\beta_{6} \\
& * x 17_{i}+\beta_{7} * x 19_{i}+\beta_{8} * x 25_{i}+\beta_{9} * x 53_{i}+\beta_{10} * x 55_{i} \\
& +\beta_{11} * x 5_{i}+\beta_{12} * x 6_{i}+\beta_{13} * x 8_{i}+\beta_{14} * x 9_{i}+\beta_{15} \\
& * x 52_{i}+\beta_{16} * x 66_{i}+\beta_{17} * x 28_{i}+\varepsilon_{i}
\end{array}
$$

где, $\beta \_\mathrm{i}-$ коэффициенты регрессии.

$$
\begin{array}{rl}
x 1_{i t}=\alpha_{i}+\beta_{1} & * x 56_{i t}+\beta_{2} * x 57_{i t}+\beta_{3} * x 18_{i t}+\beta_{4} * x 39_{i t}+\beta_{5} * x 41_{i t} \\
& +\beta_{6} * x 17_{i t}+\beta_{7} * x 19_{i}+\beta_{8} * x 25_{i t}+\beta_{9} * x 53_{i t}+\beta_{10} \\
& * x 55_{i t}+\beta_{11} * x 5_{i t}+\beta_{12} * x 6_{i t}+\beta_{13} * x 8_{i t}+\beta_{14} * x 9_{i t} \\
& +\beta_{15} * x 52_{i t}+\beta_{16} * x 66_{i t}+\beta_{17} * x 28_{i t}+\varepsilon_{i t}
\end{array}
$$

где, $\alpha \_$i - выражает индивидуальный эффект объекта i, не зависящий от времени t, при этом регрессоры не содержат константу.

$$
\begin{array}{rl}
x 1_{i t}=\mu+\beta_{1} * & x 56_{i t}+\beta_{2} * x 57_{i t}+\beta_{3} * x 18_{i t}+\beta_{4} * x 39_{i t}+\beta_{5} * x 41_{i t} \\
& +\beta_{6} * x 17_{i t}+\beta_{7} * x 19_{i}+\beta_{8} * x 25_{i t}+\beta_{9} * x 53_{i t}+\beta_{10} \\
& * x 55_{i t}+\beta_{11} * x 5_{i t}+\beta_{12} * x 6_{i t}+\beta_{13} * x 8_{i t}+\beta_{14} * x 9_{i t} \\
& +\beta_{15} * x 52_{i t}+\beta_{16} * x 66_{i t}+\beta_{17} * x 28_{i t}+u_{i t}+\varepsilon_{i t}
\end{array}
$$

где, $\mu$ - константа, $u_{-}$it - случайная ошибка, инвариантная по времени для каждого объекта.

$$
\begin{array}{rl}
x 1_{i t}=\alpha_{i}+\rho * & W * x 1_{i t}+\beta_{1} * x 56_{i t}+\beta_{2} * x 57_{i t}+\beta_{3} * x 18_{i t}+\beta_{4} \\
& * x 39_{i t}+\beta_{5} * x 41_{i t}+\beta_{6} * x 17_{i t}+\beta_{7} * x 19_{i}+\beta_{8} * x 25_{i t} \\
& +\beta_{9} * x 53_{i t}+\beta_{10} * x 55_{i t}+\beta_{11} * x 5_{i t}+\beta_{12} * x 6_{i t}+\beta_{13} \\
& * x 8_{i t}+\beta_{14} * x 9_{i t}+\beta_{15} * x 52_{i t}+\beta_{16} * x 66_{i t}+\beta_{17} \\
& * x 28_{i t}+\varepsilon_{i t}
\end{array}
$$

где, W - матрица, характеризующая пространственную компоненту в модели, $\rho-$ коэффициент, отражающий наличие пространственных эффектов.

$$
\begin{array}{rl}
x 1_{i t}=\mu+\rho * & W * x 1_{i t}+\beta_{1} * x 56_{i t}+\beta_{2} * x 57_{i t}+\beta_{3} * x 18_{i t}+\beta_{4} \\
& * x 39_{i t}+\beta_{5} * x 41_{i t}+\beta_{6} * x 17_{i t}+\beta_{7} * x 19_{i}+\beta_{8} * x 25_{i t} \\
& +\beta_{9} * x 53_{i t}+\beta_{10} * x 55_{i t}+\beta_{11} * x 5_{i t}+\beta_{12} * x 6_{i t}+\beta_{13} \\
& * x 8_{i t}+\beta_{14} * x 9_{i t}+\beta_{15} * x 52_{i t}+\beta_{16} * x 66_{i t}+\beta_{17} \\
& * x 28_{i t}+u_{i t}+\varepsilon_{i t}
\end{array}
$$


где, $\mu$ - константа, $u_{-}$it - случайная ошибка, инвариантная по времени для каждого объекта.

\section{Результаты}

Результаты оцененных моделей приведены в табл. 2.

Таблиия 2

Результаты оцененных моделей

\begin{tabular}{|c|c|c|c|c|c|}
\hline & (1) & (2) & (3) & (4) & (5) \\
\hline VARIABLES & Pooled & FE & $\mathrm{RE}$ & SAR_FE & SAR_RE \\
\hline \multirow[t]{2}{*}{$\begin{array}{l}\text { Реальные доходы на душу насе- } \\
\text { ления }\end{array}$} & $19.235^{*}$ & 2.733 & $13.725^{*}$ & 4.384 & $13.009 *$ \\
\hline & $(11.080)$ & (7.847) & (7.578) & (7.123) & $(7.276)$ \\
\hline \multirow[t]{2}{*}{ Уровень образованности } & $-7,663.549 * * *$ & 559.778 & -243.133 & 976.357 & 408.251 \\
\hline & $(1,168.228)$ & $(892.655)$ & $(883.141)$ & (812.640) & (841.840) \\
\hline \multirow{2}{*}{$\begin{array}{l}\text { Коэффициент демографической } \\
\text { нагрузки }\end{array}$} & 0.080 & $0.257 * * *$ & $0.244 * * *$ & $0.126^{* *}$ & $0.101 * *$ \\
\hline & $(0.059)$ & $(0.052)$ & $(0.049)$ & $(0.051)$ & $(0.051)$ \\
\hline \multirow{2}{*}{$\begin{array}{l}\text { Уровень развития финансовой } \\
\text { инфраструктуры в регионе }\end{array}$} & 0.095 & 0.079 & 0.042 & 0.060 & 0.028 \\
\hline & $(0.066)$ & $(0.066)$ & $(0.056)$ & $(0.060)$ & $(0.054)$ \\
\hline \multirow{2}{*}{ Уровень преступности } & -0.003 & -0.003 & -0.003 & -0.002 & -0.003 \\
\hline & $(0.006)$ & $(0.006)$ & $(0.005)$ & $(0.005)$ & $(0.005)$ \\
\hline \multirow[t]{2}{*}{ Уровень присутствия женщин } & $0.508 * * *$ & 0.065 & -0.002 & 0.136 & 0.072 \\
\hline & $(0.080)$ & $(0.180)$ & $(0.113)$ & $(0.164)$ & $(0.113)$ \\
\hline \multirow[t]{2}{*}{ Уровень брачности } & $7.777 * * *$ & -1.023 & -0.699 & -0.540 & -0.351 \\
\hline & $(2.815)$ & $(1.575)$ & $(1.581)$ & (1.431) & $(1.491)$ \\
\hline \multirow[t]{2}{*}{ Уровень безработицы } & $-5.106 * * *$ & 0.756 & 0.352 & 0.768 & 0.507 \\
\hline & $(0.790)$ & $(0.565)$ & $(0.558)$ & $(0.513)$ & $(0.529)$ \\
\hline \multirow[t]{2}{*}{ Уровень автомобилизации } & $-0.166 * * *$ & 0.028 & 0.021 & 0.034 & 0.023 \\
\hline & $(0.051)$ & $(0.049)$ & $\begin{array}{l}(0.047) \\
\end{array}$ & $(0.044)$ & $(0.045)$ \\
\hline \multirow{2}{*}{ Склонность к кредитованию } & $3.613^{* * *}$ & $-3.404 * * *$ & $-2.998 * * *$ & -1.324 & -0.833 \\
\hline & $(1.727)$ & (1.174) & $(1.158)$ & (1.119) & (1.137) \\
\hline \multirow[t]{2}{*}{$\begin{array}{l}\text { Уровень обеспеченности боль- } \\
\text { ничными койками }\end{array}$} & $1.299 * * *$ & 0.003 & 0.214 & 0.002 & 0.156 \\
\hline & $(0.214)$ & $(0.196)$ & $(0.188)$ & $(0.177)$ & $(0.180)$ \\
\hline \multirow[t]{2}{*}{$\begin{array}{l}\text { Уровень обеспеченности вра- } \\
\text { чами }\end{array}$} & $-0.312 * * *$ & $-0.451 * * *$ & $-0.433 * * *$ & $-0.406 * * *$ & $-0.384 * * *$ \\
\hline & $(0.071)$ & $(0.091)$ & $(0.083)$ & $(0.083)$ & $(0.080)$ \\
\hline \multirow[t]{2}{*}{$\begin{array}{l}\text { Склонность к заболеваниям си- } \\
\text { стемы кровообращения }\end{array}$} & 0.416 & 0.093 & 0.150 & 0.046 & 0.083 \\
\hline & $(0.284)$ & $(0.177)$ & $(0.177)$ & $(0.161)$ & $(0.167)$ \\
\hline \multirow[t]{2}{*}{$\begin{array}{l}\text { Склонность к заболеваниям } \\
\text { крови, кроветворных органов и } \\
\text { отдельные нарушения, вовлека- } \\
\text { ющие иммунный механизм }\end{array}$} & $2.103 * * *$ & $2.021 * * *$ & $1.392 * *$ & $2.005^{* * *}$ & $1.608 * * *$ \\
\hline & $(0.648)$ & $(0.636)$ & $(0.590)$ & $(0.577)$ & $(0.566)$ \\
\hline \multirow[t]{2}{*}{$\begin{array}{l}\text { Уровень развития дорожной } \\
\text { сети }\end{array}$} & $-0.022 *$ & -0.009 & $-0.033 * *$ & -0.008 & $-0.025^{*}$ \\
\hline & $(0.012)$ & $(0.021)$ & $(0.014)$ & $(0.019)$ & $(0.014)$ \\
\hline \multirow[t]{2}{*}{$\begin{array}{l}\text { Уровень выбросов загрязняю- } \\
\text { щих веществ } \\
\end{array}$} & -6.856 & $8.169^{* *}$ & $10.762 * * *$ & $7.973^{* *}$ & $9.552 * * *$ \\
\hline & $(4.511)$ & $(3.678)$ & (3.573) & $(3.336)$ & (3.393) \\
\hline \multirow[t]{2}{*}{$\begin{array}{l}\text { Уровень производительности } \\
\text { труда }\end{array}$} & $0.000 * * *$ & $0.000 * * *$ & $0.000 * * *$ & $0.000 * * *$ & $0.000 * * *$ \\
\hline & $(0.000)$ & $(0.000)$ & $(0.000)$ & $(0.000)$ & $(0.000)$ \\
\hline Constant & $-373.523 * * *$ & 168.994 & $220.796^{*}$ & & -1.553 \\
\hline
\end{tabular}




\begin{tabular}{|c|c|c|c|c|c|}
\hline & $(93.307)$ & $(213.859)$ & (131.703) & & $(135.928)$ \\
\hline \multicolumn{6}{|l|}{ Spatial } \\
\hline rho & & & & $0.561 * * *$ & 0.631 *** \\
\hline & & & & $(0.092)$ & $(0.085)$ \\
\hline Observations & 747 & 747 & 747 & 747 & 747 \\
\hline R-squared & 0.482 & 0.371 & & 0.090 & \\
\hline AIC & 8394 & 6613 & & 6584 & \\
\hline BIC & 8477 & 6696 & & 6667 & \\
\hline Number of REGION & & 83 & 83 & 83 & 83 \\
\hline
\end{tabular}

Источник: составлено авторами

\section{Обсуждение результатов}

С учетом результата теста Хаусмана наиболее предпочтительной моделью является SAR_FE c AIC 6584. Рассмотренные нами факторы оказывают как положительное, так и отрицательное влияние на склонность к заболеваемости органов дыхания населения. Среднее значение величины склонности к заболеваниям органов дыхания жителей соседних регионов положительно влияет на соответствующую величину региона - это и есть основной результат исследования.

Коэффициент демографической нагрузки имеет значимое положительное влияние на склонность к заболеваниям органов дыхания, то есть, чем больше лиц нетрудоспособного возраста приходится на 1000 человек трудоспособного возраста, тем выше будет показатель заболеваемости. Это может быть связано с тем, что человек возвращаясь в семью, контактирует с большим количеством людей, у которые потенциально могут заболеть. Уровень обеспеченности врачами имеет отрицательное влияние. Наличие врачей в регионе также играет немаловажную роль в обеспечении здравоохранения людей, которые там проживают. Следовательно, если в регионе будет мало врачей, то заболеваемость органов дыхания у людей будет возрастать, так как если в момент заражения человек не обратился вовремя к доктору за помощью или не получил вовремя эту помощь, то он может передать свою болезнь другим людям. Склонность к заболеваниям крови, кроветворных органов и отдельные нарушения, вовлекающие иммунный механизм, положительно влияет. Если иммунитет человека не в порядке, то вероятность того, что он заразится каким-либо легочным заболеванием, будет довольно высокой. Уровень развития дорожной сети отрицательно влияет. Возможно, это связано с тем, что регионы с более высокими доходами могут больше заботиться об экологии, например, высаживать деревья. Здесь требуется реализовать отдельное исследование данных эффектов. Уровень выбросов загрязняющих веществ имеет положительное влияние. Уровень производительности труда положительно влияет. Высокая производительность труда в регионе может быть связано с накоплением производственных мощностей. С другой стороны, может иметь значение высокий уровень интенсивности труда. Также, как уже было отмечено ранее, работники с большей вероятностью контактировать на рабочих местах с теми, у кого могут быть подобного рода заболевания.

\section{Заключение}

С помощью построенных моделей продемонстрировано влияние различных социально-экономических факторов на склонность людей к заболеваниям органов дыхания, а также межпространственное взаимовлияние. Так, выводы работы подтверждают результаты исследований на зарубежных выборках, демонстрирующих влияние уровня выбросов загрязняющих веществ на склонность к заболеваниям органов дыхания местного населения. 
На основе полученных результатов можно более обоснованно описывать причины межрегиональной дифференциации исследуемого показателя. Полученные данные могут стать опорным материалом для разработки дальнейших действий со стороны государства по уменьшению смертности населения от различных болезней органов дыхания. Отрицательное влияние выявленных факторов на заболеваемость можно уменьшить благодаря проведению грамотной политики в области медицины, урбанизации (строительство городов, дорог) и экономики.

В дальнейшем предстоит провести анализ склонности к широкому кругу заболеваний с выявлением перекрестных эффектов взаимовлияния.

\section{Список источников / References}

1. Liqun Liua, Xiaoyan Liua, Xiangyun Ma, Bofu Ning, Xia Wan. Analysis of the associations of indoor air pollution and tobacco use with morbidity of lung cancer in Xuanwei, China. Science of the Total Environment, 2020, vol. 717, no. 135232, pp. 1-8. DOI: 10.1016/j. scitotenv.2019.135232

2. Carlos Torres-Duque, Darıo Maldonado, Rogelio Perez-Padilla, Majid Ezzati, and Giovanni Vieg. Biomass Fuels and Respiratory Diseases. Forum of International Respiratory Societies Report, 2008, vol. 5, no. 5, pp. 577-590. DOI: 10.1513/pats.200707-100RP

3. Adama Sana, Serge Somda, Nicolas Meda, Catherine Bouland. Chronic obstructive pulmonary disease associated with biomass fuel use in women: a systematic review and meta-analysis. BMG Open Respiratory Research, 2018, vol. 5, no. 000246, pp. 1-10. DOI: 10.1136/bmjresp-2017-000246

4. Ozlem Kar Kurt, Jingjing Zhang and Kent E. Pinkerton. Pulmonary health effects of air pollution. Current Opinion Pulmonary Medicine, 2016, vol. 22, no.2, pp. 138-143. DOI: 10.1097/MCP.0000000000000248

5. Jonathan Ciencewicki \& Ilona Jaspers. Air Pollution and Respiratory Viral Infection. Inhalation Toxicology, 2007, vol. 19, no 14, pp. 1135-1146. DOI: 10.1080/08958370701665434

6. Annunziata Faustini, Massimo Stafoggia, Paola Colais, Giovanna Berti,Luigi Bisanti, Ennio Cadum, Achille Cernigliaro, Sandra Mallone,Corrado Scarnato and Francesco Forastiere. Air pollution and multiple acute respiratory outcomes. Eur Respir J, 2013, vol. 42, no. 2, pp. 304313. DOI: $10.1183 / 09031936.00128712$

7. Deshmukh, P., Kimbrough, S., Krabbe, S., Logan, R., Isakov, V., Baldauf, R. Identifying air pollution source impacts in urban communities using mobile monitoring. Science of the Environment, 2020, vol. 715, no. 136979, pp. 1-14. DOI: 10.1016/j.scitotenv.2020.136979

8. Walker, E.S., Clark, M.L., Young, B.N., Rajkumar, S., Benka-Coker, M.L., Bachand, A.M., Brook, R.D., Nelson, T.L., Volckens, J., Reynolds, S.J., L’Orange, C., Africano, S., Osorto Pinel, A.B., Good, N., Koehler, K., Peel, J.L. Exposure to household air pollution from biomass cookstoves and self-reported symptoms among women in rural Honduras. International Journal of Environmental Health Research, 2019, vol. 30, no. 2, pp. 160-173. DOI: 10.1080/09603123.2019.1579304

9. Grzywa-Celińska, A., Krusiński, A., Milanowski, J. 'Smoging kills' - Effects of air pollution on human respiratory system. Annals of Agricultural and Environmental Medicine, 2020, vol. 27, no. 1, pp. 1-5. DOI: 10.26444/aaem/110477

10. Ravindra, K., Kaur-Sidhu, M., Mor, S. Air pollution in rural households due to solid biomass fuel use and its health impacts. Lecture Notes in Civil Engineering, 2020, vol. 60, pp. 27-33. DOI: 10.1007/978-981-15-1334-3_4

11. Eguiluz-Gracia, I., Mathioudakis, A.G., Bartel, S., Vijverberg, S.J.H., Fuertes, E., Comberiati, P., Cai, Y.S., Tomazic, P.V., Diamant, Z., Vestbo, J., Galan, C., Hoffmann, B. The need for clean air: The way air pollution and climate change affect allergic rhinitis and asthma. Allergy: European Journal of Allergy and Clinical Immunology, 2020, vol. 75, no. 9, pp. 2170-2184. DOI: 10.1111/all.14177

12. F. J. Kelly and J. C. Fussell. Air pollution and airway disease. Clinical \& Experimental Allergy, 2011, vol. 41, no. 8, pp. 1059-1071. DOI: 10.1111/j.1365-2222.2011.03776.x 
13. Lidia Panico, Mel Bartley, Michael Marmot, James Y. Nazroo, Amanda Sacker and Yvonne J. Kelly. Ethnic variation in childhood asthma and wheezing illnesses: findings from the Millennium Cohort Study. International Journal of Epidemiology, 2007, vol. 36, no. 5, pp. 1093 1102. DOI: $10.1093 / \mathrm{ije} / \mathrm{dym} 089$

14. Philip J. Cooper, Laura C. Rodrigues and Mauricio L. Barreto. Influence of poverty and infection on asthma in Latin America. Current Opinion Allergy Clinical Immunology, 2012, vol. 12, no. 2, pp. 171-178. DOI: 10.1097/ACI.0b013e3283510967

15. О. Б. Перова, Л. П. Агулова, Л. П. Волкотруб. Связь заболеваемости туберкулезом органов дыхания в Томской области с экологическими и социально-экономическими факторами. Вестник Томского государственного университета, 2013, №370, сс. 179182. [O. B. Perova, L. P. Agulova, L. P. Volkotrub. Svjaz' zabolevaemosti tuberkulezom organov dykhanija $\mathrm{v}$ Tomskoi oblasti s ekologicheskimi i sotsial'no-ekonomicheskimi faktorami. [The relationship between the incidence of respiratory tuberculosis in the Tomsk region and environmental and socio-economic factors]. Vestnik Tomskogo gosudarstvennogo universiteta $=$ Bulletin of Tomsk State University, 2013, no.370, pp.179-182.]

16. Федеральная служба государственной статистики. Регионы России. Социально-экономические показатели. Москва, Росстат, 2019, 1024 с. [Federal'naja sluzhba gosudarstvennoj statistiki. Regiony Rossii. Social'no-jekonomicheskie pokazateli [Regions of Russia. Socio-economic indicators]. Moskva, Rosstat, 2019, 1024 p.]

\section{Сведения об авторах / About authors}

Нагапетян Артур Рубикович, канд. экон. наук, старший преподаватель Департамента экономических наук, Школа экономики и менеджмента, Дальневосточный федеральный университет. 690022 Россия, г. Владивосток, о-в Русский, кампус ДВФУ, корпус G.

E-mail: nagapetyan_ar@dvfu.ru

Artur R. Nagapetyan, Candidate of Economic Sciences, Senior Lecturer at the Department of Economic Sciences, School of Economics and Management, Far Eastern Federal University. Building G, FEFU campus, Russky Island, Vladivostok, Russia 690922. E-mail: nagapetyan_ar@dvfu.ru

Попов Максим Александрович, студент, Школа экономики и менеджмента, Дальневосточный федеральный университет. 690022 Россия, г. Владивосток, о-в Русский, кампус ДВФУ, корпус G. Email: popov.mal@students.dvfu.ru

Maksim A. Popov, Student, School of Economics and Management, Far Eastern Federal University. Building G, FEFU campus, Russky Island, Vladivostok, Russia 690922.

E-mail: popov.mal@students.dvfu.ru

Петрухина Анастасия Сергеевна, студент, Школа экономики и менеджмента, Дальневосточный федеральный университет. 690022 Россия, г. Владивосток, о-в Русский, кампус ДВФУ, корпус G. Email: petrukhina.ase@students.dvfu.ru

Anastasia S. Petrukhina, Student, School of Economics and Management, Far Eastern Federal University. Building G, FEFU campus, Russky Island, Vladivostok, Russia 690922.

E-mail: petrukhina.ase@students.dvfu.ru 